\title{
Complications and predictors of diagnostic yield of endobronchial forceps biopsy in visible lesions
}

\author{
'Bishow Kumar Shrestha, 'Shital Adhikari, 'Binay Kumar Thakur, 'Dipen Kadaria, \\ ${ }^{4}$ Kishore Kumar Tamrakar, ${ }^{2}$ Mukti Devkota
}

\author{
'Pulmonary, Critical Care and Sleep Medicine Unit, Chitwan Medical College Teaching Hospital, Chitwan, Nepal \\ ${ }^{2}$ Department of Thoracic Surgery, B P Koirala Memorial Cancer Hospital, Chitwan, Nepal \\ ${ }^{3}$ Division of Pulmonary, Critical Care and Sleep Medicine, University of Tennessee HSC, Memphis, TN, USA \\ ${ }^{4}$ Department of Surgery, Chitwan Medical College Teaching Hospital, Chitwan, Nepal
}

Keywords: Bronchoscopy; forceps biopsy;

exophytic growth; predictors

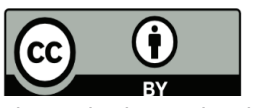

This work is licensed under a Creative Commons Attribution 4.0 Unported License.

\section{Abstract}

Background: Fiberoptic bronchoscopy is an important and relatively safe procedure for evaluation of various pulmonary diseases. Endobronchial forceps biopsy is commonly performed sampling technique for visible lesions in tracheobronchial tree. Diagnostic yield of biopsy depends upon lesion type and the number of biopsy samples taken. This study aimed to evaluate the complications and diagnostic yield of endobronchial forceps biopsy in visible lesions and correlate the number of biopsy samples taken with the yield.

Methods:

This was an observational study conducted at two tertiary care hospitals in Chitwan; Chitwan Medical College Teaching Hospital and B P Koirala Memorial Cancer Hospital. One hundred and forty patients who underwent endobronchial forceps biopsy of bronchoscopically visible lesions were included. Complications and diagnostic yield of the biopsy samples and its correlation with number of biopsies taken were evaluated.

Results:

The common complications observed were transient drop in saturation $>4 \%(22 \%)$ and mild bleeding (9.9\%). The net diagnostic yield was $67.4 \%$ that significantly improved with an increase in the number of biopsies taken. The yield was better for exophytic growths compared to submucosal/ mucosal lesions ( $83.7 \%$ vs. $57 \%, \mathrm{OR}=8.1(2.2-29.9), \mathrm{P}<0.001)$. The association of improved yield with increased number of biopsy was more pronounced in exophytic growths compared to submucosal/mucosal lesions.

Conclusion:

Endobronchial forceps biopsy is a safe procedure that gives a good diagnostic yield in bronchoscopically visible lesions, provided adequate number of biopsy sample are taken. The probability of getting a positive yield is high in exophytic growths.

\section{Introduction}

Fiberoptic bronchoscopy (FOB) has greatly revolutionized the field of pulmonary medicine and has been the procedure of choice for diagnosis of various pulmonary diseases. ${ }^{1}$ It is a safe procedure that can be performed under local anaesthesia and provides maximal visualization of tracheobronchial tree in short time. ${ }^{2}$ FOB is primarily used to obtain tissue samples for histologic

\section{Corresponding Author}

Dr Bishow Kumar Shrestha, Pulmonary, Critical Care and Sleep Medicine Unit, Chitwan Medical College Teaching Hospital, Bharatpur - 10, Chitwan, Nepal. Email: bishow.ccm@gmail.com,

Phone: +9779801072179 
examination. Various conventional bronchoscopic sampling techniques are bronchial wash and bronchoalveolar lavage, bronchial brushing, transbronchial and endobronchial needle aspiration, and transbronchial and endobronchial forceps biopsy. The practice of sampling technique depends upon skill and experience of the operator and resources available for sample acquisition.

Bronchoscopic samples collected by multiple sampling techniques give better diagnostic yield than any of the techniques alone.3-5 Endobronchial forceps biopsy (EBB) of bronchoscopically visible lesions is commonly utilized sampling technique. Visibility of the endobronchial lesions and the numbers of biopsy sample taken are regarded as good predictors of diagnostic yield. The visible lesions that can be biopsied generally are categorized as exophytic growth and submuocsal/mucosal infiltrative lesion.6 Very few studies have attempted to correlate the yields of EBB in these two categories of visible lesions. The aims of this study were to find the complications associated with EBB and its diagnostic yield in visible lesions, and to correlate the number of biopsy samples with positive yield.

\section{Methods:}

After obtaining ethical clearance from Institutional Review Boards, this cross-sectional observational study was conducted over a period of 3 months (March 2018 - May 2018) at Chitwan Medical College Teaching Hospital (CMCTH), Chitwan and B P Koirala Memorial Cancer Hospital (BPKMCH), Chitwan. A total of 140 consecutive patients who underwent EBB (EBB rate: $56.9 \%$ ) were included. A written informed consent was taken from all the participants of the study.

A detailed clinical data including age, gender, symptoms, smoking status, comorbidities, clinical and radiological (based on CT scan chest) indications for bronchoscopy and routine investigations results were recorded in proforma at the time of enrolment in the study. At least 6 hours fasting prior to the procedure was made mandatory and an intravenous line was accessed in all the patients.

After thoroughly explaining the procedure to the patient, $10 \%$ lidocaine was sprayed onto oropharynx and $2 \%$ lidocaine jelly was put into the nostril. Briefly following topical anaesthesia, bronchoscopy was performed, mostly through trans-nasal route in supine position, using Fujinon EB-530T bronchoscope with working channel $2.8 \mathrm{~mm}$ in CMCTH or PENTAX 1000 series bronchoscope with working channel $2 \mathrm{~mm}$ in BPKMCH, whose distal ends were lubricated with $2 \%$ lidocaine jelly prior to insertion. Bronchoscopy was performed via trans-oral route with mouth guard in 5 patients (3.5\%). All the patients received oxygen supplementation by nasal cannula, started 2 to 5 minutes prior to the procedure and were continuously monitored with cardiac monitor and pulse oximeter.

Local anaesthesia was supplemented with aliquots of 1 to 2 millilitres of $1 \%$ lidocaine solution through the procedure port for topical bronchial anaesthesia as needed, not exceeding $300 \mathrm{mg}$ of lidocaine in total. None of the patient received sedation during the procedure.

Thorough examination of tongue base, epiglottis, valeculla, aryepiglottic folds, pyriform fossa, vocal cords, upper airways and tracheobronchial tree was performed. Bronchoscopically visible endobronchial lesions were classified as exophytic growth, submucosal/mucosal infiltrative lesions and extrinsic compression. Exophytic growth included fleshy or friable polypoidal, cauliflower, nodular or multiodular endobronchial growth. Submucosal/mucosal infiltrative lesions included loss of normal bronchial markings, mucosal irregularity, erythema or vascular flares, mucosal/submucosal thickening causing none to minimal luminal narrowing. Extrinsic compression consisted of luminal narrowing due to peribronchial lesions with or without abnormalities of overlying mucosa/submucosa. EBBs were obtained from both the types of lesion viz exophytic growth and infiltrative submucosal/mucosal lesions. EBB was not performed in normal appearing mucosa/submucosa overlying extrinsic compression. When both exophytic growth and infiltrative lesions were found in the same patient, EBBs were taken from exophytic growth only. All the biopsy samples were immediately transferred to Formaldehyde containing container.

The number of biopsies taken was decided by several factors like discomfort to the patient, probability of excessive bleeding and oxyhemoglobin desaturation during the procedure. In each case, biopsies were attempted till the operator/brocnhoscopist felt that the samples were adequate or the biopsy procedure had to be stopped prematurely due to complication.

Decline in oxyhemoglobin saturation during bronchoscopy was managed by increasing the oxygen supplementation, withdrawing bronchoscope into the trachea, jaw thrust and suctioning out secretions. Severity of bleeding was assessed as per BTS guidelines $(2013)^{7}$ as no bleeding, mild bleeding, moderate bleeding and severe bleeding. Cold saline and diluted adrenaline solution were kept ready during the procedure. All the patients were kept under constant supervision for assessing postbronchoscopy complication with advice of nil per oral for 2 hours. The bronchsocopic findings, number of biopsies taken from the lesion type and complications observed were mentioned in the bronchoscopy report, which were later recorded in the proforma.

The biopsy samples were sent for histologic examination at the earliest possible. All the samples were examined and interpreted by consultant pathologists of the respective hospitals. Histopathology reports that mentioned "sample inadequate for analysis" $(n=5)$ were excluded from yield calculation and the report that mentioned "suspicious for malignancy" $(n=3)$ were taken as positive yield and included in the yield calculation.

The data collected were entered and analyzed using IBM SPSS Statistics 20 . The data were presented as mean $( \pm S D)$, frequency (percentage). Multivariate logistic regression analysis was used to calculate the effect size of possible predictors of diagnostic yield of the bronchoscopic biopsy procedure.

Results

The baseline data of the patients is shown in Table 1

\begin{tabular}{|l|l|}
\hline \multicolumn{2}{|l|}{$\begin{array}{l}\text { Table 1: Baseline data of different variables of the patients } \\
(n=140)\end{array}$} \\
\hline Variables & Variables \\
\hline Age & $61.72 \pm 12.38$ years \\
\hline $\begin{array}{l}\text { Sex } \\
\text { Male } \\
\text { Female }\end{array}$ & $69(48.9 \%)$ \\
\hline \multicolumn{1}{|c|}{ Comorbidities } & $72(51.1 \%)$ \\
Yes & $77(54.6 \%)$ \\
No & $64(45.4 \%)$ \\
\hline
\end{tabular}




\begin{tabular}{|c|c|}
\hline $\begin{array}{l}\text { Chief complaints } \\
\text { Cough } \\
\text { Hemoptysis } \\
\text { Dyspnea } \\
\text { Chest pain } \\
\text { Fever } \\
\text { Hoarseness of voice } \\
\text { Weight loss } \\
\text { Dysphagia }\end{array}$ & $\begin{array}{l}112(79.4 \%) \\
72(51.1 \%) \\
54(38.3 \%) \\
41(29.1 \%) \\
12(8.5 \%) \\
11(7.8 \%) \\
11(7.8 \%) \\
2(1.4 \%)\end{array}$ \\
\hline $\begin{array}{l}\text { Smoking status } \\
\text { Ex-smoker } \\
\text { Current smoker } \\
\text { Non-smoker }\end{array}$ & $\begin{array}{l}64(45.4 \%) \\
66(46.8 \%) \\
11(7.8 \%)\end{array}$ \\
\hline $\begin{array}{l}\text { Radiological indication } \\
\text { Mass } \\
\text { Collapse/consolidation } \\
\text { Nodule } \\
\text { Cavitating mass } \\
\text { Cavity } \\
\text { Parenchymal infiltration } \\
\text { Patchy opacity } \\
\text { Repeat bronchoscopy (for } \\
\text { inconclusive previous } \\
\text { bronchoscopy) }\end{array}$ & $\begin{array}{l}111(78.7 \%) \\
35(24.8 \%) \\
16(11.3 \%) \\
9(6.4 \%) \\
5(3.5 \%) \\
1(0.7 \%) \\
1(0.7 \%) \\
7(5.0 \%)\end{array}$ \\
\hline $\begin{array}{l}\text { Ext r a - p a r e } \mathrm{n} \mathrm{h} \text { y } \mathrm{m} \text { a I } \\
\text { manifestations } \\
\text { Pleural effusion } \\
\text { SVC syndrome } \\
\text { Supraclavicular lymph node }\end{array}$ & $\begin{array}{l}15(10.6 \%) \\
9(6.4 \%) \\
6(4.2 \%) \\
1(0.7 \%)\end{array}$ \\
\hline
\end{tabular}

Out of 140 patients, $37.1 \%(52 / 140)$ had biopsies taken from exophytic growths and the remaining $62.9 \%$ from submucosal/ mucosal infiltrative lesions.

The median number of biopsies taken was 5 (Range: $2-8$ ). The diagnostic yield increased significantly with the increase in the number of biopsies taken (Table 2)

\begin{tabular}{|c|c|}
\hline Number of biopsies taken & Diagnostic yield (\%) \\
\hline $3(n=18)$ & $10.5 \%$ \\
\hline $4(n=45)$ & $40.0 \%$ \\
\hline $5(n=65)$ & $98.5 \%$ \\
\hline $6(n=5)$ & $100.0 \%$ \\
\hline $8(n=2)$ & $100.0 \%$ \\
\hline
\end{tabular}

The most common complication observed was transient drop in saturation $>4 \%$ (22.0\%). Mild bleeding occurred in 9.9\%, which was significantly associated with presence of superior vena cava obstruction (SVCO) (incidence of mild bleeding: $60.0 \%$ vs. 8.1 $\%$ in patients with and without SVCO respectively, $\mathrm{P}<0.001)$. Bradycardia and transient fever occurred in 1\% each.

Table 3 shows the distribution of histopathological diagnoses obtained. The net diagnostic yield was $67.4 \%$. Diagnosis of "suspicious for malignancy" was made in 3 patients (2.2\%).

\begin{tabular}{|c|c|}
\hline Diagnosis & $\mathrm{N}(\%)$ \\
\hline $\begin{array}{l}\text { Lung malignancy } \\
\text { SCLC* } \\
\text { NSCLC } \\
\text { Squamous cell carcinoma } \\
\text { Adenocarcinoma } \\
\text { Morphologically } \\
\text { unclassifiable NSCLC } \\
\text { Small round cell tumor } \\
\text { Typical carcinoid tumor }\end{array}$ & $\begin{array}{l}81(60.0 \%) \\
22 \\
56 \\
14 \\
4 \\
38 \\
2(1.5 \%) \\
1(0.7 \%)\end{array}$ \\
\hline Chronic inflammatory lesion & $6(4.4 \%)$ \\
\hline TB & $1(0.7 \%)$ \\
\hline Suspicious for malignancy & $3(2.2 \%)$ \\
\hline No diagnosis made & $44(32.6 \%)$ \\
\hline
\end{tabular}

*SCLC: Small Cell lung cancer **NSCLC: Non-small cell lung cancer

Overall, the diagnostic yield increased significantly with increase in the number of biopsies taken. The yield was $98.5 \%(n=65)$ with 5 and $100 \%(n=6)$ with 6 biopsy samples. There was a significant difference in diagnostic yield between the patient group where $<4$ biopsies were taken and patient group where $\geq 4$ biopsies were taken $(10.5 \%$ vs. $73.6 \%, \mathrm{P}<0.001)$.

On subgroup analysis, diagnostic yield of biopsies taken from exophytic growth was $83.7 \%$ (41/49) and that from submucosal/ mucosal infiltrative lesion was $57.0 \%$ (49/86) (Table 4). The diagnostic yield was significantly higher in the patient group that had $\geq 4$ biopsies (for both exophytic growth and submucosal/ mucosal infiltrative lesion) compared to $<4$ biopsies $[95.2 \%$ vs. $14.3 \%$ for exophytic growth, $64.9 \%$ vs. $8.3 \%$ for infiltrative lesion, $\mathrm{P}<0.001)$.

\begin{tabular}{|r|r|r|}
\hline \multicolumn{3}{|l}{$\begin{array}{l}\text { Table 4. Number of biopsies, diagnostic yield and lesion types } \\
\text { in the study population }\end{array}$} \\
\hline Number of biopsies & $\begin{array}{r}\text { Diagnostic yield } \\
\text { from exophytic } \\
\text { growth (\%) } \\
(\mathrm{n}=49)\end{array}$ & $\begin{array}{r}\text { Diagnostic yield from } \\
\text { infiltrative lesions (\%) } \\
(\mathrm{n}=86)\end{array}$ \\
\hline 3 & $14.3 \%$ & $8.3 \%$ \\
\hline 4 & $77.8 \%$ & $30.5 \%$ \\
\hline 5 & $100.0 \%$ & $97.1 \%$ \\
\hline 6 & $100.0 \%$ & $100.0 \%$ \\
\hline 8 & - & $100.0 \%$ \\
\hline & & $57.0 \%$ \\
\hline $\begin{array}{l}\text { Overall diagnostic } \\
\text { yield }\end{array}$ & & \\
\hline
\end{tabular}

After multivariate logistic regression, it was found that the number of biopsies taken and the type of bronchoscopically visible lesion significantly predicted diagnostic yield. The odds of getting positive diagnostic yield was 8.1 times higher when the sample was taken from exophytic growth compared to infiltrative lesion. Similarly, the diagnostic yield reduced by $98.5 \%$ when $<4$ biopsies were taken from the samples compared to $\geq 4$ biopsies. (Table 5 ) 


\begin{tabular}{|c|r|r|}
\hline \multicolumn{3}{|c|}{$\begin{array}{l}\text { Table 5. Predictors of diagnostic yield [Odds ratio }(95 \% \mathrm{Cl})] \\
\text { in multivariate logistic regression analysis }\end{array}$} \\
\hline $\begin{array}{c}\text { Bronchoscopic } \\
\text { biopsy taken } \\
\text { from }\end{array}$ & aOR $(95 \% \mathrm{Cl})^{*}$ & \multicolumn{2}{|c|}{ P-value } \\
\hline Infiltrative lesion & 1 & 0.002 \\
\hline $\begin{array}{c}\text { Exophytic growth } \\
\text { Number of } \\
\text { biopsies }\end{array}$ & $2.104(2.198-$ & \\
\hline$\geq 4$ biopsies & $29.873)$ & \\
\hline$<4$ biopsies & $0.015(0.003-$ & \\
\hline
\end{tabular}

* adjusted for age and gender

\section{Discussion:}

Flexible bronchoscopy is the most commonly performed procedure to diagnose various pulmonary diseases including lung cancer. Endobronchial forceps biopsy (EBB) of bronchoscopically visible lesions (exophytic endobronchial growth and submucosal/ mucosal bronchial infiltration) has variable diagnostic yields ranging from $48 \%$ to $97 \% .^{8-11}$

In this study, lung mass was the most common radiological indication for bronchoscopy (78.7\%), with majority of them presenting with cough. The most common histopathological diagnosis was lung malignancy $(60 \%)$, the most common being non-small cell lung cancer (NSCLC). These finding are in close agreement with a recent study by Dhungana $A$ et al. ${ }^{12}$ This observation however is incongruent with the recent trend of rising adenocarcinoma incidence, both in men and women.13 This disparity could be because majority of NSCLC diagnosed in our study was morphologically undifferentiated and immunohistochemistry staining was not performed to differentiate NSCLC subtypes.

The incidence of major complications like cardiac arrest and death is extremely low for bronchoscopy, which is also observed in this study. ${ }^{14,15}$ Majority of the complications observed were minor and self-resolving, the most frequent being transient drop in oxygen saturation $>4 \%$, which occurred in $22 \%$ of the patients. Gibson et al. ${ }^{16}$ and Grendelmeier $\mathrm{P}$ et al. ${ }^{17}$ also observed closely similar incidences of transient hypoxemia.

Mild bleeding was observed in $9.9 \%$ of the patients that stopped spontaneously after minimal suctioning. This is slightly higher than that reported in other study. ${ }^{18}$ The probable reason for this could be our study included only those patients who underwent EBB. EBB is associated with more incidences of bleeding than when bronchoscopy was performed without it. ${ }^{19,20}$ In our study, bleeding incidence was significantly higher in patients with superior vena cava obstruction, which is consistent with finding of other investigators. ${ }^{21}$

Our result (net diagnostic yield of $67.4 \%$ ) is comparable with the study by Rivera MP et al.10 but is lower than the studies that reported yields over $85 \% .^{22,23}$ The reason for lower yield in our study could be attributed to higher number of patients with submucosal/mucosal infiltrative lesions that have proven lower diagnostic yield than exophytic growths., ${ }^{5,6,24}$ Besides, the yield of EBB is also affected by several other factors like necrotic tissue overlying the biopsy-site, crushing artifact of biopsied tissue in the bronchoscope channel, size of the biopsied tissue, experience of the operator (bronchoscopist) and the number of biopsy samples taken. ${ }^{5,25-28}$

The diagnostic yield for patients with exophytic growth was higher compared to patients with submucosal/mucosal infiltrative lesion ( $83.7 \%$ vs. $57 \%)$. This is in agreement with study by Kacar et al. ${ }^{25}$ that reported similar yields for exopytic growth (86.4\%) and infiltrative/peribronchial lesions (47.2\%).

EBB specimens generally are small and contain small number of malignant cells. ${ }^{29}$ Coghlin et al. 30 reported that not every biopsy sample contained tumour cells, with the mean percentage area of tumour in an endobronchial biopsy sample being 33\% and fewer than half the cases contained tumour in all biopsy samples. In our study, the net diagnostic yield improved significantly with increase in the number of EBB taken and reached almost $100 \%$ when 5 or more EBB samples were taken. This is consistent with the study by Gellert AR et al. 4 which reported the frequency of at least one specimen with evidence of carcinoma increased to $96 \%$ with 5 and $100 \%$ with 6 biopsy specimens. In our study, the difference in net diagnostic yield was significantly higher in patient group where $\geq 4$ biopsies were taken (73.6 vs. $10.5 \%, p<0.001)$. This observation is supported by other studies that reported higher diagnostic yield with increased number of biopsy specimens. ${ }^{5,24,26}$ Several studies suggested bronchoscopic visibility, tumoursize and location as significant predictors of higher diagnostic yields. ${ }^{31-33}$ We found that the odds of obtaining diagnostic yield was 8.1 times higher when EBB were taken from exophytic growth compared to infiltrative lesions. The probable reason for this finding could be that the tumour cell burden of exophytic growth and infiltrative lesion vary; the burden being higher in the exophytic growth increasing the probability of picking up sample with tumour cells.

This is an observational study and sample size is relatively small and may fall short to validate these findings in general. But it highlights the need of sufficiently powered larger study to confirm our findings, i.e., to ensure satisfactory yield, what minimum number of EBB is required from these two different categories of the visible lesions in different disease states.

\section{Conclusion:}

Endobronchial forceps biopsy is a safe procedure with few minor complications. The yield of EBB increased as the number of biopsy samples increased and satisfactory yield was obtained with minimum of five biopsy samples both in exophyitc growths and submucosal/mucosal infiltrative lesions. However, the odd of getting positive diagnosis with EBB was high in exophytic growth. 


\section{References}

1. Joos L, Patuto N, Chhajed PN, Tamm M. Diagnostic yield of flexible bronchoscopy in current clinical practice. Swiss medical weekly. 2006;136(9-10):155-9.

2. Suratt $P$, Smiddy J, Gruber B. Deaths and complications associated with fiberoptic bronchoscopy. Chest. 1976;69:74751.

3. Kvale PA, Bode FR, Kini S. Diagnostic accuracy in lung cancer; comparison of techniques used in association with flexible fiberoptic bronchoscopy. Chest. 1976;69(6):752-7.

4. Gellert AR, Rudd RM, Sinha G, Geddes DM. Fibreoptic bronchoscopy: effect of multiple bronchial biopsies on diagnostic yield in bronchial carcinoma. Thorax. 1982;37(9):684-7.

5. Roth K, Hardie JA, Andreassen AH, Leh F, Eagan TM. Predictors of diagnostic yield in bronchoscopy: a retrospective cohort study comparing different combinations of sampling techniques. BMC pulmonary medicine. 2008;8:2.

6. Patil S, Rujuta A. Bronchoscopic Characterization of Lesions: Significant impact on lung cancer diagnosis with use of Transbronchial needle aspiration (TBNA) in Comparison to conventional diagnostic techniques (CDTs). Clinical Cancer Investigation Journal. 2017;6(6):239-46.

7. Du Rand IA, Blaikley J, Booton R, Chaudhuri N, Gupta V, Khalid $\mathrm{S}$, et al. British Thoracic Society guideline for diagnostic flexible bronchoscopy in adults: accredited by NICE. Thorax. 2013;68 Suppl 1:i1-i44.

8. Saita S, Tanzillo A, Riscica C, Maresca A, Potenza E, D'Arrigo $M$. Bronchial brushing and biopsy: a comparative evaluation in diagnosing visible bronchial lesions. European journal of cardio-thoracic surgery : official journal of the European Association for Cardio-thoracic Surgery. 1990;4(5):270-2.

9. Rivera MP, Mehta AC. Initial diagnosis of lung cancer: ACCP evidence-based clinical practice guidelines (2nd edition). Chest. 2007;132(3 Suppl):131s-48s.

10. Rivera MP, Mehta AC, Wahidi MM. Establishing the diagnosis of lung cancer: Diagnosis and management of lung cancer, 3rd ed: American College of Chest Physicians evidence-based clinical practice guidelines. Chest. 2013;143(5 Suppl):e142Se65s.

11. Agarwal A GL, Garbyal RS, Mital VP, Chokhani R. Evaluation of Pulmonary Malignancies in Kathmandu Valley and Role of Bronchoscopic Techniques in Diagnosis of such Cases. JIACM 2003;4(2):127-33.

12. Dhungana A, Bhattarai D, Shrestha P, Acharya N. Lung Cancer in a Tertiary Hospital in Nepal: Clinical-Radiological Profile and Histological Subtypes. Journal of Nepal Health Research Council. 2020;17(4):463-7.

13. Barta JA, Powell CA, Wisnivesky JP. Global Epidemiology of Lung Cancer. Annals of global health. 2019;85(1).

14. Adewole OO, Onakpoya UU, Ogunrombi $A B$, Komolafe $A$, Odeyemi AD, Adeniran S, et al. Flexiblefiberoptic bronchoscopy in respiratory care: Diagnostic yield, complications, and challenges in a Nigerian Tertiary Center. Nigerian journal of clinical practice. 2017;20(1):77-81.

15. Asano F, Aoe M, Ohsaki Y, Okada Y, Sasada S, Sato S, et al. Deaths and complications associated with respiratory endoscopy: a survey by the Japan Society for Respiratory Endoscopy in 2010. Respirology (Carlton, Vic). 2012;17(3):478-85.

16. Gibson PG, Breit SN, Bryant DH. Hypoxia during bronchoalveolar lavage. Australian and New Zealand journal of medicine. 1990;20(1):39-43.

17. Grendelmeier P, Kurer G, Pflimlin E, Tamm M, Stolz D. Feasibility and safety of propofol sedation in flexible bronchoscopy. Swiss medical weekly. 2011;141:w13248.

18. Bernasconi M, Koegelenberg CFN, Koutsokera A, Ogna A,
Casutt A, Nicod L, et al. latrogenic bleeding during flexible bronchoscopy: risk factors, prophylactic measures and management. ERJ open research. 2017;3(2).

19. Cordasco EM, Jr., Mehta AC, Ahmad M. Bronchoscopically induced bleeding. A summary of nine years' Cleveland clinic experience and review of the literature. Chest. 1991;100(4):1141-7.

20. Pue CA, Pacht ER. Complications of fiberoptic bronchoscopy at a university hospital. Chest. 1995;107(2):430-2.

21. Carr IM, Koegelenberg CF, von Groote-Bidlingmaier F, Mowlana A, Silos K, Haverman T, et al. Blood loss during flexible bronchoscopy: a prospective observational study. Respiration; international review of thoracic diseases. 2012;84(4):312-8.

22. Zavala DC. Diagnostic fiberoptic bronchoscopy: Techniques and results of biopsy in 600 patients. Chest. 1975;68(1):12-9.

23. Popp W, Rauscher H, Ritschka L, Redtenbacher S, Zwick H, Dutz W. Diagnostic sensitivity of different techniques in the diagnosis of lung tumors with the flexible fiberoptic bronchoscope. Comparison of brush biopsy, imprint cytology of forceps biopsy, and histology of forceps biopsy. Cancer. 1991;67(1):72-5.

24. McLean AN, Semple PA, Franklin DH, Petrie G, Millar EA, Douglas JG. The Scottish multi-centre prospective study of bronchoscopy for bronchial carcinoma and suggested audit standards. Respiratory medicine. 1998;92(9):1110-5.

25. Kacar N, Tuksavul F, Edipoglu O, Ermete S, Guclu SZ. Effectiveness of transbronchial needle aspiration in the diagnosis of exophytic endobronchial lesions and submucosal/peribronchial diseases of the lung. Lung cancer (Amsterdam, Netherlands). 2005;50(2):221-6.

26. Karahalli E, Yilmaz A, Turker H, Ozvaran K. Usefulness of various diagnostic techniques during fiberoptic bronchoscopy for endoscopically visible lung cancer: should cytologic examinations be performed routinely? Respiration; international review of thoracic diseases. 2001;68(6):611-4.

27. Gellert AR, Rudd RM, Sinha G, Geddes DM. Fibreoptic bronchoscopy: effect of experience of operator on diagnostic yield of bronchial biopsy in bronchial carcinoma. British journal of diseases of the chest. 1982;76(4):397-9.

28. Herth FJF. Bronchoscopic techniques in diagnosis and staging of lung cancer. Breathe. 2011;7(4):324-37.

29. Ofiara LM, Navasakulpong A, Ezer N, Gonzalez AV. The importance of a satisfactory biopsy for the diagnosis of lung cancer in the era of personalized treatment. Current oncology (Toronto, Ont). 2012;19(Suppl 1):S16-23.

30. Coghlin CL, Smith LJ, Bakar S, Stewart KN, Devereux GS, Nicolson MC, et al. Quantitative analysis of tumor in bronchial biopsy specimens. Journal of thoracic oncology : official publication of the International Association for the Study of Lung Cancer. 2010;5(4):448-52.

31. Castella J, Buj J, Puzo C, Anton PA, Burgues C. Diagnosis and staging of bronchogenic carcinoma by transtracheal and transbronchial needle aspiration. Annals of oncology : official journal of the European Society for Medical Oncology. 1995;6 Suppl 3:S21-4.

32. Stringfield JT, Markowitz DJ, Bentz RR, Welch MH, Weg JG. The effect of tumor size and location on diagnosis by fiberoptic bronchoscopy. Chest. 1977;72(4):474-6.

33. Baaklini WA, Reinoso MA, Gorin AB, Sharafkaneh A, Manian P. Diagnostic yield of fiberoptic bronchoscopy in evaluating solitary pulmonary nodules. Chest. 2000;117(4):1049-54. 